\title{
Determinación y prevalencia de Mycobacterium spp., en tilapia nilótica (Oreochromis niloticus) cultivada en Campeche, México
}

\section{Determination and prevalence of Mycobacterium spp., in Nile tilapia (Oreochromis niloticus) cultured in México}

\author{
Maurilio Lara-Flores, ${ }^{1 *}$ Ph.D, Sara Balan-Zetina, ${ }^{1}$ Biol, Ana Zapata, ${ }^{1}$ Biol, \\ Karina Sonda-Santos, ${ }^{1}$ Biol.
} ¿Universidad Autónoma de Campeche,Instituto de Ecología, Pesquerías y Oceanografía del Golfo de
México. San Francisco de Campeche, Campeche, México. *Correspondencia:maurlara@uacam.mx

Recibido: Julio de 2011; Aceptado: Agosto de 2012.

\begin{abstract}
RESUMEN
Objetivo. Determinar la presencia y prevalencia de Mycobacterium spp., en granjas de tilapia nilótica (Oreochromis niloticus) en el Municipio de Champotón, Campeche, México. Materiales y métodos. La colecta de organismos se realizó en tres granjas de cultivo de tilapia nilótica del municipio de Champotón, Campeche, México. Los organismos se examinaron externa e internamente y se tomó una muestra de riñón la cual fue sembrada en forma de estría en medios de cultivo: LöwesnteinJensen, TCBS, $\mathrm{KF}$ y en TSA; las placas fueron incubadas a $35^{\circ} \mathrm{C}$ de 24 a 48 horas, los órganos fueron fijados en formalina tamponada al $10 \%$ para ser procesados para histología de rutina para análisis posteriores. Asimismo, muestras de cultivo bacteriológico y de tejido fueron teñidas con la técnica de Ziel-Neelsen con el fin de observar la presencia de bacilos ácido-alcohol resistentes. Resultados. Los resultados obtenidos sugieren que la presencia de Mycobacterium spp., es constante y en alta prevalencia y puede ser un factor que este mermando la rentabilidad del cultivo. Conclusiones. La presencia de Mycobacterium spp., representa un riesgo para el cultivo de tilapia en el municipio de Champotón, por ser una enfermedad muy persistente y difícil de erradicar una vez ocurrido e brote de infección, por lo cual es importante llevar estudios más detallados de la presencia de este género bacteriano, así como, medidas de prevención y dispersión de este patógeno en los cultivos adyacentes.
\end{abstract}

Palabras clave: Acuicultura, enfermedades de peces, Oreochromis niloticus, México (Fuente: IEDCYT) 


\section{ABSTRACT}

Objective. Determine the presence and prevalence of Mycobacterium spp., at tilapia (Oreochromis niloticus) farms in the municipality of Champotón, Campeche, Mexico. Materials and methods. The collection of organisms was conducted in three farms of Nile tilapia at Champotón township, Campeche, Mexico. The organisms were examined externally and internally and a kidney sample was inoculated in different growth media: Löwestein-Jensen, TCBS, KF and TSA. The plates were incubated at $35^{\circ} \mathrm{C}$ for 24 to 48 hours, the organs were fixed in $10 \%$ buffered formalin to be processed for routine histology for further analysis. Likewise, bacterial culture samples and tissue were stained through the Ziel-Neelsen technique to observe the presence of acid-fast bacilli. Results. The results suggest that the presence of Mycobacterium spp., is constant and its high prevalence and could be an undermining issue in the profitability of this culture. Conclusions. The presence of Mycobacterium spp., represents a risk for tilapia culture in the municipality of Champotón, it is a very persistent and difficult to eradicate disease once an outbreak has occurred, reason for which it is important to bring more detailed studies of the presence of this bacterial genus, as well as prevention and spread of this pathogen in adjacent cultures.

Key words: Aquaculture, fish diseases, Oreochromis niloticus, Mexico (Source: IEDCYT).

\section{INTRODUCCIÓN}

Actualmente la acuacultura constituye una actividad que contribuye con la alimentación de muchas comunidades del mundo, ya que la pesca está llegando a sus límites máximos de producción debido a la sobreexplotación de algunas especies, la degradación del ambiente, la contaminación de las aguas y los costos producidos por el alza de los precios de los combustibles (1).

El objetivo principal de la acuacultura es la producción de especies acuáticas, para consumo humano o repoblación de especies amenazadas, manipulando o controlando los ecosistemas de aguas dulces, salobres o saladas, en medios naturales o sistemas artificiales (1).

Una de las principales amenazas a la sustentabilidad de la acuacultura son las enfermedades, por lo que desde inicios de los 80 's, diversas organizaciones han creado comisiones especializadas encargadas de promover la sanidad en animales acuáticos y prevenir la transmisión de enfermedades a través de su comercio nacional e internacional (1).

El desarrollo y crecimiento de la acuacultura tecnificada con el consecuente incremento en los niveles de intensificación de los cultivos, enfrenta riesgos cada vez mayores de incidencia y dispersión de enfermedades en las poblaciones acuáticas. La mayor amenaza en los cultivos son las enfermedades por virus, bacterias u otros agentes causales de patologías que dada su rapidez de acción, dispersión y alto grado de afectación, pueden llegar a ser difíciles de eliminar o controlar (2-4).
La enfermedad no puede considerarse como un proceso de carácter monofactorial sino de carácter multifactorial lo que lleva a contemplarlo como un proceso dependiente de todo el entorno en que se desarrolla el organismo, incluidos el animal hospedero, el agente etiológico, las características de calidad del medio como las fisicoquímicas, biológicas y la manipulación del hombre (5).

El estudio de las enfermedades acuáticas se ha enfocado principalmente en cultivos de peces y camarón, donde comienzan brotes que se desarrollan con rapidez ocasionando tasas de mortandad altas y que, en algunos casos, tienden a desaparecer con igual rapidez (enfermedades agudas) o por otro lado, se desarrollan con menor velocidad y menor severidad pero que se encuentran persistentes por largos periodos (enfermedades crónicas) (6).

Las enfermedades bacterianas se caracterizan en: 1 ) erosión en el cuerpo; 2) daños en los ojos, 3 ) erosión o fusión de las branquias, 4) petequias, $5)$ ascitis y 6$)$ adelgazamiento del cuerpo $(7,8)$. Entre los agentes etiológicos de origen bacteriano más importantes Gram-negativo se encuentran los grupos Enterobacteriaceas, Vibronaceas, Aeromonadáceas y Pseudomonadáceas. Por otro lado, entre los Gram-positivo más importantes se pueden mencionar a los cocos y bacilos como: Streptococcus, Lactococcus, Renibacterium, Micobacteriáceas y Nocardiáceas (9-12).

Particularmente una enfermedad contagiosa puede ocurrir por la virulencia del patógeno, las condiciones del ambiente y la conductividad e 
inducción de la enfermedad (13). Normalmente el estrés no es siempre el factor decisivo para accionar un brote de infección; muchas bacterias como $A$. salmonicida y $M$. marinum son patógenos que pueden presentarse en un mínimo de estrés (13).

Actualmente una de las enfermedades que ha aumentado la frecuencia de infección en los cultivos acuícolas de peces tropicales es la micobacteriosis; esta es el resultado de una infección por una de varias especies de Mycobacterium. Jacobs et al (14) mencionan que las infecciones por Mycobacterium spp., deben tratarse diferente a otras enfermedades bacterianas por sus propiedades patógenas, ya que las especies de Mycobacterium han demostrado resistencia al sistema inmunológico del pezy también son resistentes a los antibióticos utilizados habitualmente en acuacultura; son extremadamente resistentes porque tienen una pared celular que impide la penetración de un desinfectante común requiriendo dosis altas.

La micobacteriosis se ha descrito en más de 160 especies de peces. Es una enfermedad aguda o crónica, dependiendo de las tasas de crecimiento de la especie y los factores ambientales del medio en que se desarrollan los peces, caracterizada por la presencia de granulomas en los órganos viscerales. Algunos organismos pueden mostrar signos externos de la enfermedad y otros no. Entre los signos que se presentan, tanto internos como externos, se encuentran: Granulomas en el exterior (principalmente en la boca), anorexia, inflamación abdominal, deformación en el cuerpo, exoftalmia unilateral o bilateral, cambio de color, descamación, hemorragias en las aletas y órganos internos, granulomas en bazo, riñón e hígado $(7,14)$; lo anterior ocasiona la mortandad masiva de los cultivos y pérdidas económicas importantes para el sector productivo.

Cabe destacar que en muchas ocasiones no sepresentan signos clínicos de la enfermedad $y$ es hasta cuando el organismo se expone a algún estresor ambiental que la enfermedad se manifiesta; por lo anterior es importante seguir un plan de monitoreo en las granjas para detectar el agente patógeno y poder realizar acciones preventiva $\mathrm{y} / \mathrm{o}$ correctivas antes que provoque la perdida del cultivo. Por otro lado, algunas de las especies de micobacterias son zoonóticas, siendo responsables en el hombre de ocasionar ulceraciones en manos y brazos, las cuales, no son fáciles de erradicar pasando de meses a años; siendo los principales pacientes adultos mayores y que típicamente están relacionados con la manipulación de peces y actividades recreacionales $(7,14,15)$.
El trabajo tuvo como objetivo determinar la presencia y prevalencia de Mycobacterium spp., en granjas de cultivo de tilapia nilótica del municipio de Champotón, Campeche, México.

\section{MATERIALES Y MÉTODOS}

Área de estudio. El municipio de Champotón se encuentra situado en la zona centro del Estado de Campeche, entre los meridianos 89.32'y $91^{\circ} 08^{\prime}$ de longitud oeste y entre los $17^{\circ} 49^{\prime} y$ $19^{\circ} 4^{\prime}$ de latitud norte. Limita al norte con el municipios de Campeche y Hopelchen, al sur con el municipio de Calakmul y al oeste con el municipio del Carmen y el Golfo de México. Cuenta con una extensión territorial de $6.088 \mathrm{~km}^{2}$ lo que representa el $10.7 \%$ del total del Estado.

En este municipio se localiza el río Champotón, desde Canasayab hasta Champotón, con una longitud de $47 \mathrm{~km}$. Su cuenca es de $6080 \mathrm{~km}^{2}$ y su escurrimiento anual asciende a $885000 \mathrm{~m}^{3}$. El clima es variado, predominan los vientos cálidos provenientes del este y sureste. Con temperaturas máximas de $40^{\circ} \mathrm{C}$ en el mes de mayo y las mínimas de 10 a $14^{\circ} \mathrm{C}$ en el mes de enero.

Estación de muestreo y tipo de muestreo. El presente estudio se llevó a cabo en complejos acuícolas de las comisarías de Canasayab, El Zapote y Santa Cruz de Rovira. El cultivo se realiza en jaulas para engorda de tilapia nilótica (O. niloticus) pertenecientes a tres líneas genéticas: hibrido de nilótica (O. niloticus $\times 0$. mossambicus), tilapia Stirling (O. niloticus) y tilapia brasileña (O. niloticus brasiliencies). Los peces son adquiridos de proveedores locales y de otros estados como Yucatán, Tabasco y Chiapas. De acuerdo a la Office International de Epizooties (OIE) (15), el tipo de muestreo que se llevó a cabo es el de tipo monitoreo o de rutina que recomienda para poblaciones de animales que no presentan registros de enfermedades. La frecuencia del muestreo fue bimestral y los meses se alternaron de acuerdo a las zonas donde se distribuyen los complejos, así como, el ciclo de producción de los mismos. Los organismos fueron colectados al azar con el propósito de determinar si el cultivo se encuentra libre de enfermedades.

Tamaño de muestra. El tamaño de muestra objetivo fue de 30 organismos, en etapa juvenil y de pre-engorde, por muestreo y está determinado con base a las tablas epidemiológicas (15) con un nivel de confianza del $95 \%$ asumiendo una prevalencia del $10 \%$ para el muestreo, considerando que la población objetivo fue mayor a los 10,000 individuos por granja. La captura de organismos se llevó a cabo con una red cuchara. 
Trabajo de campo. Una vez tomada la muestra de organismos, se procedió a examinar la parte externa e interna de los peces capturados con la finalidad de determinar la posible presencia de alguna anomalía obvia de enfermedad.

Para llevar a cabo el examen interno se sacrificó al pez por medio de una severación espinal que se realizó haciendo un corte transversal en la parte dorsal-posterior de la cabeza.

Los órganos de los peces (dependiendo del tamaño), fueron fijados y preservados en formalina amortiguada al $10 \%$ en agua destilada, después de 72 horas, fueron transferidos a etanol al $50 \%$ para ser procesados para histología de rutina. Aparte de las muestras tomadas directamente de los órganos, la tinción Ziel-Neelsen (HYCEL ${ }^{\text {MR }}$ 64293) también se practicó sobre cortes histológicos de ejemplares que presentaron granulomas típicos de micobacteriosis.

Análisis bacteriológico. Para determinar la prevalencia de Mycobacterium spp., en las distintas granjas, se procedió a tomar una muestra del riñón. En presencia de signos clínicos externos se tomaron muestras de otros órganos como: bazo, hígado, así como ulceraciones características, y en caso muy particular se tomaron muestras de sangre.

Las muestras fueron inoculadas por estría en medios de cultivo sólidos. Se utilizaron por espécimen un medio general de Agar de Soya y Tripticaseína (TSA, Bioxon $\mathrm{MR}^{4343986)}$ y medios selectivos: Agar KF (Difco ${ }^{\text {TM }}$ 249610), Agar TCBS (Dibico ${ }^{T M}$ 1079R91) y Medio LöwesteinJensen (Difco ${ }^{\mathrm{TM}}$ 244420) este último preparado en tubos inclinados. Las placas sembradas fueron guardadas en bolsas de plástico y a baja temperatura para su transporte al laboratorio. Se incubaron las muestras a una temperatura de $35^{\circ} \mathrm{C}$, y cada 24 horas se examinaron.

Para diferenciar los grupos bacterianos concomitantes a la infección por Mycobacterium spp., presentes en los cultivos, se realizó una minuciosa observación de la estructura y forma de la colonia. Las colonias fueron visibles entre 24 y 48 horas, y se tomaron en cuenta las características descritas por Kimberley y Whitman (10).

Las bacterias aisladas se tiñeron mediante las técnicas de Gram (HYCEL ${ }^{\text {MR }}$ 541) y Ziel-Neelsen (HYCELMR 64293) con el objeto de determinar la morfología y composición química de bacterias.

Análisis estadístico. El análisis de prevalencia cuyo valor se expresa en porcentajes (\%), se realizó por el total de organismos colectados en el estudio y el número de organismos colectados por granja; y se calcularon en términos de organismos con lesiones, y por el resultado positivo a bacteriología.

Para analizar diferencias significativas entre la proporción de los grupos bacterianos presentes en las granjas, se realizó un análisis de $\chi^{2}$, empleando una tabla de contingencia de $2 \times 2$. Los datos utilizados no fueron convertidos, es decir no se trabajaron con los porcentajes obtenidos, sino que se trabajaron con el número de organismos que presentó cada género bacteriano, el número de organismos que no lo presentó y el total de organismos colectados.

Buller (12), señala que las enfermedades bacterianas no necesariamente son causadas por un solo género bacteriano, sino por interacciones de entre dos o más especies; estableciendo una relación de concomitancia y así obrar en conjunto para el desarrollo de la enfermedad. En este estudio, las muestras fueron obtenidas de manera independiente de cada granja,por lo tanto la probabilidad de que Mycobacterium se presente en las tres granjas es independiente, ya que las condiciones de desarrollo en el cultivo son diferentes. En estas condiciones, se calculó la probabilidad condicional de que en cada granja, se presentara Mycobacterium de manera independiente y también que se presente Vibrio y Streptococcus dado que ya existió Mycobacterium. Lo anterior se realizó en virtud que se tienen reportes de que Mycobacterium es una bacteria oportunista y solo se presenta en caso de que se presenten otros agentes patógenos. Se utilizaron los géneros Vibrio y Streptococcus ya que en trabajos previos fueron los que han sido reportados como patógenos importantes en la región en el cultivo de tilapia. Con lo anterior se puede determinar que género bacteriano puede ser considerado como oportunista obligado.

\section{RESULTADOS}

Un total de 225 organismos fueron colectados en las granjas de cultivo en nueve muestreos realizados, sin embargo no se obtuvo en la mayoría la muestra mínima establecida anteriormente por falta de cooperación por parte de los productores. Del total de organismos analizados se tiene que $78.2 \%$ (176) presentaron una o más lesiones que pudieran estar asociadas a infecciones bacterianas, donde el $29.3 \%$ corresponde a la granja de Canasayab, el $27.5 \%$ pertenece a la granja de Santa Cruz de Rovira y el $21.3 \%$ constituye la granja El Zapote (Tabla 1 ). 
Tabla 1. Porcentaje de organismos que presentaron lesiones asociadas a bacterias por granja. Entre paréntesis se muestran el número de organismos.

\begin{tabular}{lccc}
\hline \multicolumn{1}{c}{ Granjas } & $\begin{array}{c}\text { Organismos } \\
\text { con lesiones }\end{array}$ & $\begin{array}{c}\text { Organismos } \\
\text { sin lesiones }\end{array}$ & $\begin{array}{c}\text { Total de } \\
\text { organismos }\end{array}$ \\
\hline Canasayab & $29.3 \%(66)$ & $10.2 \%(23)$ & 89 \\
$\begin{array}{l}\text { Sta. Cruz de } \\
\text { Rovira }\end{array}$ & $27.5 \%(62)$ & $3.56 \%(8)$ & 70 \\
Zapote & $21.3 \%(48)$ & $8 \%(18)$ & 66 \\
\hline Total & $78.2 \%(176)$ & $21.8 \%(49)$ & 225 \\
\hline
\end{tabular}

Las lesiones internas fueron constantes en las tres granjas, sin embargo, en Santa Cruz de Rovira las lesiones externas fueron sobresalientes y constantes. Con respecto a los signos externos observados durante los muestreos se exhibieron: necrosis en aletas, ulceraciones en boca, petequia en boca y cuerpo, exoftalmia unilateral, deformidad en cola, boca y opérculo, pérdida de color; por mencionar las más importantes. Internamente se observaron: hepatopáncreas pálido e inflamado, presencia de grasa en la cavidad abdominal, bazo inflamado, branquias pálidas, intestino hemorrágico, inflamación y hemorragias en el riñón (Tabla 2).

Tabla 2. Anomalias y lesiones externas e internas más importantes de acuerdo a la prevalencia en el total de organismos colectados*

\begin{tabular}{lcl}
\hline \multicolumn{1}{c}{ Lesiones } & Casos & Origen \\
\hline Grasa en la cavidad abdominal & 71 & Interno \\
Aletas escoriadas y necróticas & 55 & Externo \\
Desordenes en el hígado & 55 & Interno \\
Desordenes en el riñón & 55 & Interno \\
Bazo inflamado & 42 & Interno \\
Petequia en boca & 25 & Externo \\
Ulcera en boca & 20 & Externo \\
Ulcera en la piel & 19 & Externo \\
Exoftalmia & 18 & Externo \\
Desordenes en la vesícula biliar & 16 & Interno \\
Necrosis en branquia & 14 & Externo \\
Deformación en boca & 12 & Externo \\
Deformación en opérculo & 11 & Externo \\
Desordenes en el intestino & 7 & Interno \\
Deformación en cuerpo & 6 & Externo \\
Ulcera en la cabeza & 6 & Externo \\
\hline
\end{tabular}

* Por cada organismo analizado se presentaron de uno a más trastornos observados

De los 225 organismos colectados $72 \%$ (161) fueron positivos a crecimiento bacteriano, en donde, el 30\% fue para Canasayab, $24 \%$ para Santa Cruz de Rovira y $17 \%$ para El Zapote (Tabla 3).

Se identificaron tres grupos bacterianos: Mycobacterium spp., Vibrio y Streptococcus; variando su prevalencia para las tres granjas de cultivo, siendo Canasayab la granja que presentó la mayor proporción de organismos
Tabla 3. Porcentaje de organismos con resultado positivo a bacteriología. Entre paréntesis se muestran el número de organismos.

\begin{tabular}{lccc}
\hline & Canasayab & $\begin{array}{c}\text { Sta. Cruz de } \\
\text { Rovira }\end{array}$ & Zapote \\
\hline $\begin{array}{l}\text { Positivo a } \\
\text { bacteriología }\end{array}$ & $76.4 \%(68)$ & $80.0 \%(56)$ & $56.1 \%(37)$ \\
Mycobacterium & $63.3 \%(43)$ & $57.1 \%(32)$ & $97 \%(36)$ \\
Vibrio & $47.0 \%(32)$ & $55.3 \%(31)$ & $29.7 \%(11)$ \\
Streptococcus & $52.9 \%(36)$ & $33.9 \%(19)$ & $18.9 \%(7)$ \\
\hline
\end{tabular}

infectados. Mycobacterium spp., fue la bacteria de mayor prevalencia en las tres granjas de cultivo, considerándose que esta bacteria podría estar contribuyendo significativamente al cuadro patológico observado. Las proporciones bacterianas fueron estadísticamente comparadas y se observó que estas son diferentes entre las granjas a pesar que los géneros bacterianos aislados fueron los mismos para los tres complejos (Tabla 3).

En la tabla 4 se presentan los resultados por granja del porcentaje de concomitancia de Vibrio y Streptococcus con respecto a Mycobacterium spp., y el número de organismos cuyo grupo bacteriano se presentó de manera independiente. Por otro lado se realizó un análisis de probabilidad condicional en cada granja para conocer la probabilidad de que exista Mycobacterium spp., de manera independiente y la posibilidad que se presenten conjuntamente los tres géneros.

En la granja Canasayab, el $25 \%$ de los organismos analizados presentó de manera independiente infección por Mycobacterium spp., el $10.2 \%$ por Vibrio y el $13.2 \%$ por Streptocossus. Por otro lado, el $13.2 \%$ de los organismos infectados por Mycobacterium spp., mostró cierta concomitancia con Vibrio y el $14.7 \%$ con Streptococcus. Sin

Tabla 4. Prevalencia de concomitancia entre grupos bacterianos aislados en la diferentes granjas del Municipio de Champotón, Campeche.

\begin{tabular}{|c|c|c|c|c|}
\hline \multicolumn{5}{|c|}{ Granja de Canasayab } \\
\hline & Mycobacterium & Vibrio & Streptococcus & Relación 3 \\
\hline Mycobacterium & $25.0 \%$ & & & \\
\hline Vibrio & $13.2 \%$ & $10.2 \%$ & & \\
\hline Streptococcus & $14.7 \%$ & $11.7 \%$ & $13.2 \%$ & \\
\hline
\end{tabular}

Relación $3 \quad 11.7 \%$

\begin{tabular}{lcccc}
\hline \multicolumn{5}{c}{ Granja de Santa Cruz de Rovira } \\
\hline Mycobacterium & $25.8 \%$ & & \\
Vibrio & $17.8 \%$ & $19.6 \%$ & \\
Streptococcus & $5.3 \%$ & $12.5 \%$ & $10.7 \%$ & $5.3 \%$ \\
Relación 3 & & & \\
\hline \multicolumn{5}{c}{ Granja El Zapote } \\
\hline Mycobacterium & $62.1 \%$ \\
Vibrio & $16.2 \%$ & $2.7 \%$ & \\
Streptococcus & $5.4 \%$ & $0.0 \%$ & $0.0 \%$ & \\
Relación 3 & & & $13.5 \%$ \\
\hline
\end{tabular}


embargo el $11.7 \%$ de los organismos exhibió de manera simultanea los tres géneros aislados.

Los resultados del análisis de probabilidad condicional muestraron la posibilidad que exista Mycobacterium spp., de manera independiente es del $51 \%$. Por otro lado la probabilidad de que se presente Vibrio es del $62 \%$ y para Steptococcuses del $66 \%$, dado que Mycobacterium spp., ya se presentó.

En Santa Cruz de Rovira los resultados mostraron que el $28.5 \%$ de los organismos presentaron infección de manera independiente por Mycobacterium spp., $19.6 \%$ por Vibrio y $10.7 \%$ solo por Streptococcus. En cambio el $17.8 \%$ de los organismos infectados por Mycobacterium spp., exhibe una relación de concomitancia con Vibrio y el $5.3 \%$ con Streptococcus. Observándose que solo el 5.3\% de los organismos presentó al mismo tiempo los tres géneros bacterianos.

Por otro lado, la probabilidad que se presente Mycobacterium spp., de manera independiente en esta granja es de $48 \%$. Sin embargo, la probabilidad de que se presente Vibrio dado que existe Mycobacterium spp., es del $80 \%$; y la posibilidad que se presente Streptococcus si ya existe Mycobacterium spp., es del $36 \%$.

En la granja Zapote se observó que el $62.1 \%$ de los organismos presentaron infección de manera independiente por Mycobacterium spp., y el $2.7 \%$ por Vibrio. En cambio el $16.2 \%$ de los organismos infectados por Mycobacterium spp., exhibió una relación de concomitancia con Vibrio y el $5.4 \%$ con Streptococcus; y el $13.5 \%$ de los organismos manifestó la presencia de los 3 géneros bacterianos.

Por otro lado, el análisis de probabilidad condicional mostró que para esta granja el $95 \%$ de los organismos presentan la posibilidad de presentar Mycobacterium spp., de manera independiente. Sin embargo, la probabilidad de que se presente Vibrio dado que existe Mycobacterium spp., es del $84 \%$; y la posibilidad de se presente Streptococcus si ya existe Mycobacterium spp., es de $53 \%$.

Los resultados del análisis de probabilidad condicional para las 3 granjas muestran que la posibilidad que exista Mycobacterium spp., de manera independiente es del $51 \%$. Por otro lado la probabilidad de que se presente Vibrio es del $62 \%$ y para Streptococcus es del $66 \%$ dado que Mycobacterium spp., ya se presentó.

\section{DISCUSIóN}

Actualmente el desarrollo de la acuacultura enfrenta riesgos cada vez mayores de incidencia y dispersión de enfermedades, diversos autores mencionan que la presencia de las enfermedades se debe al incremento en los niveles de intensificación de los cultivos. Una de las especies de mayor importancia en la acuacultura es la tilapia, porque es una especie resistente a enfermedades y por su capacidad de adaptación a ambientes diversos de cultivo $(4,17)$. Sin embargo, estas pueden presentar enfermedades a causa de un estrés ambiental severo como: una baja de temperatura, manipulación, sobrepoblación y una pobre calidad del agua; presentándose principalmente en los alevines.

Entre las enfermedades que afectan a esta especie se encuentran: el síndrome de la septicemia hemorrágica bacteriana, streptocosis, micobacteriosis y columnaris (17-19). Por tal motivo, es necesario llevar a cabo estudios que determinen los posibles patógenos en los sistemas de cultivo y así prevenir la dispersión y desarrollo de estas enfermedades. La presencia de micobacterias en granjas de cultivo y en acuarios es de importancia social, ecológica y económica. Esta enfermedad es persistente y difícil de erradicar una vez ocurrida la epizootia $(14,15,19)$, el tiempo de incubación es variable y pueden pasar años para su desarrollo hasta la muerte de los organismos causando deformidades esqueléticas $(6,15,20)$, por su importancia zoonótica en seres humanos, la presencia de este patógeno conduce a la pérdida de su valor comercial $(6,15)$.

En el presente estudio se aislaron tres géneros bacterianos de importancia patógena, sin embargo por los análisis de laboratorio realizados, la presencia de bacilos ácido-alcohol resistentes aislados de cultivo y tejido, y de granulomas presentes; se determinó que la presencia de Mycobacterium spp., puede ser la posible causa de las patologías observadas en las granjas de cultivo de tilapia en el municipio de Champotón, Campeche, México. Aunque la sintomatología observada no permite asegurar que la infección es causada únicamente por Mycobacterium, las lesiones observadas son básicamente similares a las descritas en estudios realizados tanto en peces de agua dulce y marinos, ya sea por inducción experimental o por infecciones espontáneas de micobacteriosis (20-23). Entre los signos descritos por la presencia de Mycobacterium se encuentran: pérdida de peso, necrosis y quistes en órganos internos, exoftalmia, inflamaciones cutáneas, deformaciones esqueléticas especialmente en espina dorsal y mandíbula; 
y decoloración del cuerpo $(6,20,24,25)$. En este estudio las granjas de Canasayab y Santa Cruz de Rovira se observaron signos externos como: ulceraciones en piel, exoftalmia unilateral o bilateral, inflamación abdominal, anorexia, decoloración del cuerpo, necrosis en aletas, deformación del cuerpo y hemorragias en aletas; sin embargo en El Zapote solo se observaron signos internos.

Algunos autores mencionan que la micobacteriosis es una enfermedad crónica progresiva con signos clínicos o asintomática $(6,15,23,24,26,27)$, en este caso podemos señalar que la presencia de la enfermedad fue crónica, con signos clínicos, para el caso de Santa Cruz de Rovira y Canasayab; y asintomática en el caso de la granja El Zapote. Por otro lado, estudios realizados en róbalo rayado expuestos a la presencia de Mycobacterium mencionan que los juveniles no presentaron lesiones internas y externas, mientras que en peces adultos exhiben lesiones externas e infección en los órganos internos (28). Lo anterior podría explicar la ausencia de lesiones externas en los organismos colectados en El Zapote, dado que, estos eran juveniles; en cambio en Canasayab y Santa Cruz de Rovira lo organismos colectados se encontraban en etapas más desarrolladas y por lo tanto, con mayor presencia de lesiones internas y externas.

Microscópicamente se identificaron granulomas y bacilos ácido-alcohol resistentes en órganos como branquias, submucosa gástrica, hígado y bazo; en las tres granjas. Las cuales de acuerdo a diferentes autores son una característica típica de la presencia de Mycobacterium spp $(22,24,27,29)$. Aunque estudios realizados por Tavares et al (30) no observaron dichos granulomas en tilapia $(O$. niloticus) a pesar de detectarse la enfermedad en cultivo bacteriológico, sin embargo, en este estudio se pudieron observar los granulomas característicos a la enfermedad.

Pérez et al (31) mencionan que la presencia de Mycobacterium spp., en las instalaciones de cultivo y demás cuerpos de agua representa un alto riesgo ya que puede causar mortalidades superiores al $10 \%$. En Israel la micobacteriosis es una de las enfermedades más devastadoras en los recientes años (32). Conroy (18) reporta importantes infecciones con micobacteriosis en el cultivo de tilapia en países africanos, en la región de América Central y en Cuba.

Como se ha mencionado la presencia de Mycobacterium spp., representa un alto riesgo para los cultivos y las especies nativas. Belas et al (25) mencionan que la prevalencia de micobacteriosis en especies silvestres es del
$62 \%$, observándose el mismo porcentaje en peces de acuario (23). En especies de peces marinos Kattari et al (33) reporta un porcentaje de $75 \%$. En el presente estudio la prevalencia para Canasayab fue de $63.3 \%$, para Santa Cruz de Rovira del $57 \%$ y para El Zapote de $97 \%$ observando que los porcentajes obtenidos son mayores en comparación con los autores antes mencionados. Por lo tanto, se puede mencionar que las granjas de cultivo estudiadas están siendo afectadas por la presencia de esta bacteria, sin embargo, no se conoce la ruta de infección.

Diversos autores mencionan que la presencia de esta enfermedad puede considerarse como una típica afección por manejo inadecuado de los organismos que sólo se presenta bajo condiciones inadecuadas de cultivo (carencia de luz, vitaminas, etc.) o bien por alimento contaminado con el patógeno (24); también hay que considerar que el desarrollo de la enfermedad puede presentarse por la combinación de los factores antes mencionados. A pesar que actualmente nuevas tendencias indican que el desarrollo de las enfermedades en acuacultura es ocasionada por un desequilibrio entre las variables que involucran a un sistema de cultivo, el agente, el hospedero y el medio (11); en este estudio es difícil determinar cual o cuales fueron las rutas de infección, ya que los parámetros ambientales no fueron observados, dado las características no controladas de los sistemas de cultivo. Se puede mencionar que la infección pudo haberse presentado desde que los organismos fueron introducidos a la unidad acuícola, desencadenándose una segunda fase de infección por un estrés ambiental.

Por lo anterior, se establece que la micobacteriosis es una enfermedad que limita el desarrollo de la acuacultura, apareciendo a veces en forma periódica, que puede manifestarse en forma asintomática sin ocasionar daños visibles, o bien desarrollar un cuadro clínico específico afectando a los peces, siguiendo un curso crónico, hasta la muerte de los organismos; dando como consecuencia que la granja se vea afectada en un futuro por esta enfermedad y que los organismos silvestres también se vean afectados. Por otro lado, algunas de las especies de micobacterias son zoonóticas, siendo responsables en el hombre de ocasionar ulceraciones en manos y brazos, las cuales no son fáciles de erradicar pasando de meses a años para su completa eliminación. Austin y Austin (8) mencionan que los principales pacientes son personas mayores y que típicamente están relacionados con la manipulación de peces y actividades recreacionales. Por tal motivo la presencia de estas bacterias en las granjas de cultivo son de 
importancia, pues esta actividad se lleva a cabo en jaulas colocadas en el río y laguna de estas comunidades, pudiendo ocasionar en el futuro problemas similares en humanos.

Por lo tanto es importante llevar a cabo este tipo de estudios que determinen la presencia de posibles patógenos en los organismos de cultivo y así prevenir la dispersión de enfermedades en los organismos naturales de la región y las de nuevo cultivo; evitando que en un futuro los cultivos se vean afectados por el desarrollo de estas enfermedades y la resistencia de estos patógenos que compliquen su tratamiento; dado que existen reportes que señalan los efectos negativos de las enfermedades tanto a nivel ecológico como económico. Hasta la fecha de elaboración de este trabajo no se encontraron reportes previos de esta enfermedad que afecte a los cultivos en México por lo que podemos considerar este como el primer reporte de este agente patógeno en el país.

En conclusión en las tres granjas de cultivo estudiadas, el género de mayor proporción fue Mycobacterium spp., a pesar de presentar concomitancia con el género Vibrio y
Streptococcus, observándose diferencias entre las proporciones bacterianas encontradas. Por otro lado estas proporciones fueron superiores a las citadas por los diversos autores, lo cual sugiere que la enfermedad puede causar una merma significativa al producto final en los productores. Finalmente la presencia de Mycobacterium spp., representa un riesgo para el cultivo de tilapia en el municipio de Champotón, por ser una enfermedad muy persistente y difícil de erradicar una vez ocurrido el brote de infección, por lo cual es importante llevar acabo estudios más detallados de la presencia de este género bacteriano, así como medidas de prevención y dispersión de este patógeno en los cultivos adyacentes al Municipio.

\section{Agradecimientos}

El presente trabajo fue financiado por el Fondo Mixto CONACYT-Gobierno del Estado de Campeche con clave: CAMP2004-C02-1. Al laboratorio de Histopatología del Instituto EPOMEX-UAC por el procesamiento de las muestras. A los productores del municipio de Champotón, México por su participación en el proyecto.

\section{REFERENCIAS}

1. Cifuentes LJL, Torres GMP, Frías MM. El océano y sus recursos XI, acuicultura. México: Fondo de Cultura Económica; 2000.

2. Aguirre-Guzman G, Lara-Flores M. Biología Molecular: Herramienta para identificar bacterias que afectan al camarón de cultivo. Fomix Campeche Revista 2011; 3(7):35-38.

3. Del Río-Rodriguez RE. Enfermedades en animales acuáticos cultivados. Fomix Campeche Revista 2010; 2(6):38-43.

4. Secretaría de Agricultura, Ganadería, Desarrollo Rural y Alimentación. México: Gobierno Federal de México; 2001 (acceso 16 de septiembre 2010). SAGARPA. Programa de Acuacultura y Pesca 20012006. URL Disponible en: http://www. sagarpa.gob.mx/ganaderia/Publicaciones/ Lists/Programa\%20Sectorial\%20de\%20 Agricultura\%20Ganadera\%20Desarro/ Attachments/4/Sectorialpesca.pdf

5. Olabuenga SE. FishInmmuneSystem. Gayana 2000; 64(2):205-2015. URL Disponible en: http://www.scielo.cl/ scielo.php?script $=$ sci_arttext\&pid $=$ s0717$65382000000200010 \&$ Ing $=$ es.
6. Ruiz ZI, Muzquz MJL, Ortega RC, Abadia VR, Muñoz GMJ, Garcés SA. Repercusión de la legislación comunitaria sobre acuicultura Española. España: Secretaría General de Pesca Marítima; 2003. 1-48.

7. Austin B, Austin DA. Bacterial fish pathogens: disease of farmed and wild fish. Inglaterra: Praxis Springer; 1999.

8. Austin B. Fish needs doctoring too! Microbiology Today 2002; 29:171-173.

9. Kimbereley A, Whitman N. Finfish and shellfish bacteriology manual. Estados Unidos de América: G MacNair; 2004.

10. Padros F, Furones MD. Patología bacteriana en piscicultura. Temas de actualidad 1993; 34:13-21.

11. Fouz B, Esteve GMD. Vacunación oral frente a enfermedades bacterianas en acuicultura. España: Valenciana de acuacultura S.A; 2002.

12. Madigan MT, Martinkon JM, Parker J. BrockBiología de los microorganismos (8 Edic.). España: Prentice Hall Iberia; 2000. 
13. Buller NB. Bacteria from fish and other aquatic animals: A practical identification manual. Estados Unidos de América: CABI Publishing; 2004.

14. Harikrishnan R, Balasundaram C. Modern trends in Aeromonas hydrophila disease management with fish. Rev Fish Sic 2005; 13:281-320.

15. Jacobs JM, Lazur A, Bayad A. Prevention and disinfection of Mycobacterium sp. Estados Unidos de América: in aquaculture. Maryland Sea Grant Extension, Publication; 2004.

16. OIE (Base de datos en Internet). Paris: Organización Mundial de Sanidad Animal; 2006 (acceso 13 de marzo de 2011) Disponible en: http://ww.oie.int/es/sanidadanimal-en-el-mundo/enfermedades-de-lalista-de-la-oie-2011/

17. Coyne R, Hjeltnes B, Bergh O, Andersen K, Rudra H, Smith P. Quantitative properties of data generated by examination of Aeromonas salmonicida infected fish by the standard bacteriological loop. Aquaculture 2004; 236:27-35.

18. Conroy G. Importantes enfermedades detectadas en tilapias cultivadas en América Latina. Panorama Acuícola Magazine, 2004; 6(9):20-25.

19. Lim C, Webster CD. Tilapia: biology, culture and nutrition. Estados Unidos de América: Food Products Press; 2006

20. Toranzo AE, Magariños B, Romalde JL. A review of the bacterial fish disease in mariculture systems. Aquaculture 2005; 246:37-61.

21. Descostere A, Hermans K, Haesebrouck F. Piscina micobacteriosis: a literature review covering the agent and the disease it cause in fish and humans. Vet Microbiol 2004; 99:159-166.

22. Gomez S. Tubercular lesions in two spanish Cyprinodontid fishes. Aqua Sc Cons 2001; 3:335-339.

23. Rhodes $M W$, Kator $H$, Kotob $S$, Berkum $P$, Kattari I, Vogelbein W, Floyd MM, Butler R, Quinn FD, Ottinger C, Shotts E. A unique Mycobacterium species isolated from an epizootic of striped bass (Morone saxatilis). Emerg Infect Dis 2001; 7(5):896-899.
24. Lescenko P, Matlova L, Dvorska L, Bartos M, Vuara O, Navratil S, Novotny L, Paulik I. Mycobacterial infection in aquarium fish. Vet Med Czech 2003; 48(3):71-78.

25. Reichenbach $\mathrm{KHH}$, Ahne $\mathrm{W}$, Negele RD, Ollenschlänger B, Popp W, Spieser $\mathrm{OH}$, Wolf K. Enfermedades de los peces (2 Ed). Estados Unidos de América: Acribia; 1982.

26. Belas R, Faloon P, Hannaford A. Potential applications of molecular biology to the study of fish Mycobacteriosis. Annu Rev Fish Dis 1995; 5:133-173.

27. Inglis V, Roberts RJ, Brom age NR. Bacterial diseases of fish. Inglaterra: Blackwell scientific publications; 1993.

28. Prearo M, Zanoni RG, Campo-Dall' Orto B, Pavoletti E, Florio D, Penati V, Ghittino C. Mycobacteriosis: Emerging pathologies in aquarium fish. Vet Res Commun 2004; 28:315-317.

29. Volgelbein WK, Zwerner DE, Kator H, Rhodes MW, Cardinal J. Epizootic micobacteriosis in Chesapeake Bay striped bass. 1999 March 9-11; Atlantic Beach, North Carolina. 24 th Annual eastern fish health workshop, 1999.

30. Tavares RPMJ, Massatoshi IC, Cocuzza AE, Risaffi SV. Effects of an experimental challenge with Mycobacterium marinum on the blood parameters of Nile tilapia, Oreochromis niloticus (Linnaeus, 1757). Braz Arch Biol Technol 2004; 47(6):945-953.

31. Pérez TA, Ramírez C, Vázquez A, Moronta A. Aislamiento de Mycobacterium scrofulaceum en peces silvestres de Caicara del Orinoco, Venezuela. Boletín Centro Investigaciones Biológicas 2006; 40(1):78-87.

32. Ucko $M$, Colorni $A$, Kuitt $H$, Diament $A$, Zlotkin A, Knibb WR. Strain variation in Mycobacterium marinum fish isolates. Appl Environ Microbiol 2002; 68(11):5281-5287.

33. Kattari IM, Rhodes MW, Kattari SL, Shotts EB. The evolving story of Mycobacterium tuberculosis clade members detected in fish. J Fish Dis 2006; 29:509-520. 